Article

\title{
Tuning Optical and Granulometric Properties of Gold Nanostructures Synthesized with the Aid of Different Types of Honeys for Microwave-Induced Hyperthermia
}

\author{
Anna Dzimitrowicz ${ }^{1, *(\mathbb{C})}$, Piotr Cyganowski ${ }^{2}{ }^{\mathbb{C}}$, Piotr Jamroz ${ }^{1}{ }^{\mathbb{D}}$, \\ Dorota Jermakowicz-Bartkowiak ${ }^{2}$, Malgorzata Rzegocka ${ }^{1}$, Agnieszka Cwiklinska ${ }^{1}$ and \\ Pawel Pohl ${ }^{1}$ (D) \\ 1 Department of Analytical Chemistry and Chemical Metallurgy, Faculty of Chemistry, Wroclaw University of \\ Science and Technology, Wybrzeze St. Wyspianskiego 27, 50-370 Wroclaw, Poland; \\ piotr.jamroz@pwr.edu.pl (P.J.); rzegocka.malgorzata@gmail.com (M.R.); a.cwiklinska328@gmail.com (A.C.); \\ pawel.pohl@pwr.edu.pl (P.P.) \\ 2 Department of Polymer and Carbonaceous Materials, Faculty of Chemistry, Wroclaw University of Science \\ and Technology, Wybrzeze St. Wyspianskiego 27, 50-370 Wroclaw, Poland; \\ piotr.cyganowski@pwr.edu.pl (P.C.); dorota.jermakowicz-bartkowiak@pwr.edu.pl (D.J.-B.) \\ * Correspondence: anna.dzimitrowicz@pwr.edu.pl; Tel.: +48-71-320-24-94
}

Received: 3 February 2019; Accepted: 14 March 2019; Published: 18 March 2019

\begin{abstract}
Size-controlled gold nanoparticles (AuNPs) were synthesised with solutions of three types of Polish honeys (lime, multiflower, honeydew) and used in microwave-induced hyperthermia cancer treatment. Optical and structural properties of nanostructures were optimized in reference to measurements made by using UV/Vis absorption spectrophotometry (UV/Vis), transmission electron microscopy (TEM) supported by energy-dispersive X-ray spectroscopy (EDX), X-ray diffraction (XRD), and attenuated total reflectance Fourier transformation infrared spectroscopy (ATR FT-IR). In addition, concentrations of reducing sugars and polyphenols of honeys applied were determined to reveal the role of these chemical compounds in green synthesis of AuNPs. It was found that the smallest AuNPs $(20.6 \pm 23.3 \mathrm{~nm})$ were produced using a $20 \%(w / v)$ multiflower aqueous honey solution and $25 \mathrm{mg} \cdot \mathrm{L}^{-1}$ of $\mathrm{Au}(\mathrm{III})$ ions. These AuNPs were then employed in microwave-induced hyperthermia in a system simulating metastatic tissues. This research illustrated that AuNPs, as produced with the aid of a multiflower honey solution, could be suitably used for microwave-induced heating of cancer. A fluid containing resultant Au nanostructures, as compared to water, revealed facilitated heating and the ability to maintain a temperature of $45{ }^{\circ} \mathrm{C}$ required for hyperthermia treatment.
\end{abstract}

Keywords: food products; green synthesis; nanostructures; phenolics; reducing sugars

\section{Introduction}

Gold nanoparticles (AuNPs) are classified as three-dimensional nanomaterials (NMs) in which at least one of the dimensions in the structure is less than $100 \mathrm{~nm}$ [1]. Due to their high surface to volume ratio, AuNPs display unique conductive, catalytic, optical, structural, thermal, and thermoplasmonic properties [2-7]. For that reason, they are widely utilized as conductors for flexible electronics [8], catalysts for polymerization of alkylosilanes [9], detectors for severe acute respiratory syndrome (SARS) coronavirus [10], contrast agents in X-ray imaging [11], vehicles for drug delivery [12], agents in photo-induced hyperthermia [13], and in microwave-induced hyperthermia treatment of cancer [14].

Microwave-induced hyperthermia treatment of cancer has gained a lot of interest in the past several years. This treatment is recognized as efficient and non-invasive [15], being successfully applied 
for the treatment of metastatic tissues in bones [16], breast [17-19], prostate [20], bladder [14], brain [15], and liver [21]. Since hyperthermia-based medical procedures rely on the susceptibility of metastatic tissues to be destroyed at elevated temperatures $\left(41-47^{\circ} \mathrm{C}\right)$ [22], the increase in the thermal response of the area surrounding a tumour may lead to more effective treatment. In microwave-induced hyperthermia procedures, this is achieved by applying nanofluids (NFs) that usually contain metallic nanostructures with ability to be electromagnetically excited. The most common $\mathrm{NFs}$ are $\mathrm{Fe}_{3} \mathrm{O}_{4}$-based and are effective in the hyperthermia treatment of bone metastases [16]. AuNPs are usually applied in sophisticated procedures of photo-induced hyperthermia due to the plasmonic effect that they cause [13]. However, based on our previous studies [23,24], AuNPs and PtNPs have the extraordinary ability to transfer and accumulate heat, even at ultra-trace concentrations. Therefore, it can be hypothesized that the application of functionalized AuNPs in microwave-induced hyperthermia treatment of cancer may also be very effective.

The wide-range of biomedical applications of AuNPs are related not only to their optical and structural properties, but could also be influenced by toxicity and the chemical composition of reducing and capping agents involved in their synthesis. Although many methods were described for the production of AuNPs, green methods are a promising alternative to well-known chemical methods [25]. In green synthesis, naturally occurring substances are used as reducing and stabilizing agents during AuNPs production instead of strong, and usually toxic, chemicals. For that reason, synthesized AuNPs are biogenic and biocompatible [26-28]. There are a variety of natural products reported to be suitable for green synthesis of AuNPs. Accordingly, aqueous leaf extracts prepared from Mentha piperita [28], Melissa officinalis [28], Salvia officinalis [28], Terminalia catappa [29], Rosa rugosa [30], Hibiscus rosa sinensis [31], Cinnamomum camphora [32], Eucalyptus globulus [33], Rosmarinus officinalis [33], Ziziphus zizyphus [34], and Plumbago zeylanica [35], aqueous extracts originated from blackberries, blueberries, and pomegranates [36], in addition to essential oils collected from Eucalyptus globulus [33], Rosmarinus officinalis [33], Anacardium occidentale [37], Curcuma pseudomontana [38], and some food products, including Punica granatum juices [39], coffee Arabica infusions [40], and cacao powder beverages [41] were involved in the production of AuNPs. To the best of our knowledge, only a few research groups have attempted to produce honey-based NFs containing Au nanostructures [42-44].

Honey is obtained by several from about 20,000 species of bees from nectar, pollen, and honeydew [45]. A large variety of plant species from which bees might collect nectar, pollen, or honeydew, as well as apiary location, and environmental conditions means that several types of honeys can be distinguished [46]. Among them, the most popular are flower, e.g., multi-flower, rapeseed, buckwheat, lime, or heather, and honeydew honeys made from coniferous, leaf, and fir honeydew [47]. The botanical provenience of the nectar, pollen, and honeydew, as well as environmental pollution, influence the chemical composition of honey [48], which can contain more than 400 different compounds [48]. In addition to water, which content in honey is less than $20 \%$ $(w / v)$ [45], there are many others substances, namely sugars (e.g., glucose, D-fructose, maltose) [49], aliphatic acids (e.g., formic acid, tartaric acid, citric acid, benzoic acid) [50], phenolics (e.g., quercetin, kaempferol, luteoil, rutin) [51], terpenes (e.g., monoterpenes) [52], ketones (e.g., acetoin) [53], vitamins (e.g., ascorbic acid, niacin, pyridoxine) [45], and proteins (e.g., alanine, arginine, serine, proline, phenylalanine) [45].

Application of honey in green synthesis of AuNPs is particularly interesting due to a large variety of honey types that might be used for that purpose, and their differentiated chemical compositions. For example, Philip [42] utilized an Indian natural honey solution for the production of spherical $(\sim 15 \mathrm{~nm}$ in size) AuNPs and suggested that fructose worked as a reducing agent for this. Snitka et al. [43] reported green synthesis of irregular-shaped $\sim 30 \mathrm{~nm}$ Au nanostructures using a Lithuanian natural honey solution. Finally, Sreelakshimi et al. [44] also presented the application of an Indian honey for formation of $10 \mathrm{~nm}$, spherical AuNPs with antibacterial activity towards different microorganisms such as pathogenic bacteria and fungus from Candida species. 
In this work, the possibility of applying three different types of Polish honeys, i.e., lime, multi-flower, and honeydew, for green synthesis of size-defined AuNPs with a possible use in microwave-induced hyperthermia treatment of cancer was examined. By tuning the type of applied aqueous honey solutions, the honey concentration in these solutions, as well as the concentration of $\mathrm{Au}(\mathrm{III})$ ions added to these aqueous solutions, optimal conditions, at which the smallest in size AuNPs were produced, were found by applying UV/Vis absorption spectrophotometry (UV/Vis). Then, nanofluids (NFs) containing AuNPs synthesized under these optimal conditions were characterized using transmission electron microscopy (TEM) supported by energy-dispersive X-ray spectroscopy (EDX), and X-ray diffraction (XRD). Next, attenuated total reflectance Fourier transform-infrared spectroscopy (ATR FT-IR) was applied to identify chemical compounds of honey solutions responsible for the production of AuNPs. Particularly, to reveal the role of reducing sugars and phenolic compounds in examined green synthesis of Au nanostructures, total concentrations of reducing sugars and phenolic compounds in applied honey solutions were determined using the Bertrand's method and the Folin-Ciocalteu assay, respectively. Furthermore, AuNPs of defined optical and granulometric properties were tested in a microwave radiation field, simulating procedures of hyperthermia treatment of cancer.

\section{Materials and Methods}

\subsection{Reagents and Solutions}

Three types of Polish honeys, i.e., lime, multi-flower, and honeydew, were purchased in a local supermarket. Chloroauric acid tetrahydrate $\left(\mathrm{HAuCl}_{4} \cdot 4 \mathrm{H}_{2} \mathrm{O}\right)$ was from Avantor Performance Materials (Gliwice, Poland). The Bertrand's solutions, i.e., I (CuSO 4$)$, II (a mixture of $\mathrm{NaOH}$ and $\mathrm{C}_{4} \mathrm{H}_{4} \mathrm{KNaO}_{6}$ ), and III (a mixture of $\mathrm{Fe}_{2}\left(\mathrm{SO}_{4}\right)_{3}$ and $\mathrm{H}_{2} \mathrm{SO}_{4}$ ), were prepared using proper reagents taken from Sigma-Aldrich (Steinheim, Germany). The Folin-Ciocalteu reagent $\left(3 \mathrm{H}_{2} \mathrm{O} \cdot \mathrm{P}_{2} \mathrm{O}_{5} \cdot 14 \mathrm{WO}_{3} \cdot 4 \mathrm{MoO}_{3} \cdot 10 \mathrm{H}_{2} \mathrm{O}\right)$ and $\mathrm{KMnO}_{4}$ were obtained from Sigma-Aldrich as well. Re-distilled water was used throughput. All reagents were of analytical grade or better.

\subsection{Honey-mediated Green Synthesis of AuNPs}

As the AuNPs precursor, a $500 \mathrm{mg} \cdot \mathrm{L}^{-1}$ stock solution of $\mathrm{Au}(\mathrm{III})$ ions was prepared by dissolving an appropriate amount of solid $\mathrm{HAuCl}_{4} \cdot 4 \mathrm{H}_{2} \mathrm{O}$ in $250 \mathrm{~mL}$ of re-distilled water. Next, as shown in Figure 1, a certain volume of the resultant stock solution of $\mathrm{Au}(\mathrm{III})$ ions was mixed with a certain volume of aqueous honey solutions at concentrations of $5,10,15$, or $20 \%(w / v)$; the final concentration of $\mathrm{Au}$ (III) ions in the resulting mixed solution was 25,50 , and $100 \mathrm{mg} \cdot \mathrm{L}^{-1}$ (Figure 1 ). AuNPs synthesis took place at room temperature until the colour of mixed turned to ruby-red. Afterwards, obtained $\mathrm{NFs}$ were stored in the fridge at $4{ }^{\circ} \mathrm{C}$ for subsequently analyses.

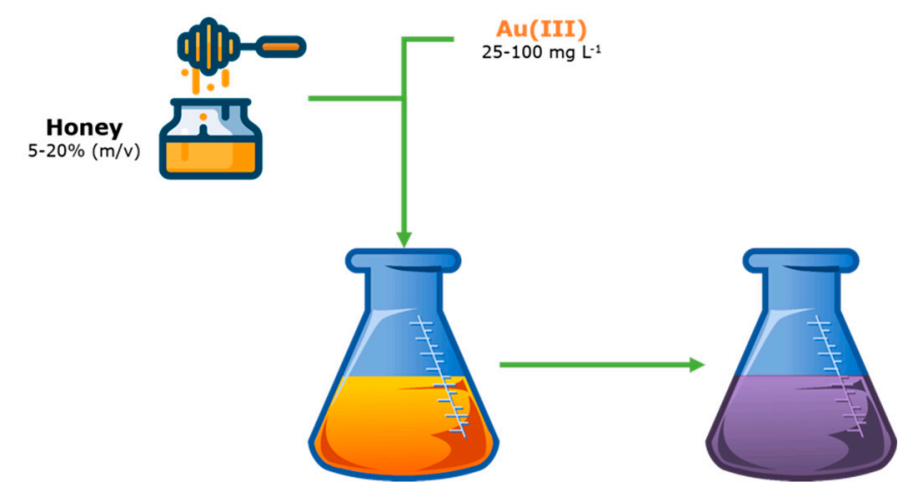

Figure 1. Green synthesis of gold nanoparticles (AuNPs). 


\subsection{Characterization of AuNPs Produced under Optimal Conditions}

To find optimal conditions for the synthesis of the smallest in size AuNPs, the effect of the type of honey (lime, multiflower, honeydew), its concentration in prepared solutions $(5,10,15$, and $20 \%(w / v))$, and the concentration of $\mathrm{Au}(\mathrm{III})$ ions $\left(25,50\right.$, and $\left.100 \mathrm{mg} \cdot \mathrm{L}^{-1}\right)$ in mixed solutions on wavelength position at maximum $\left(\lambda_{\max }\right)$ of the localized surface plasmon resonance (LSPR) absorption band of AuNPs was assessed. Optical properties of synthesized AuNPs were assessed using UV/Vis absorption spectrophotometry with a Specord 210 Plus spectrophotometer (Analytik Jena AG, Jena, Germany). These UV/Vis absorption spectra were recorded $72 \mathrm{~h}$ after AuNPs synthesis in the spectral range of 300-1100 nm, with a step of $0.1 \mathrm{~nm}$, and a scanning speed of $20 \mathrm{~nm} \cdot \mathrm{s}^{-1}$. Re-distilled water was applied to zero the spectrophotometer. UV/Vis absorption spectra of raw honey solutions, and $\mathrm{Au}(\mathrm{III})$ ions solutions were also determined.

Granulometric properties of AuNPs produced under optimal synthesis conditions were assessed using various techniques. For the determination of size, shape, and elemental composition of AuNPs, TEM (Tecnai G 20 X-TWIN, FEI, Hillsboro, OR, USA) equipped with an EDX instrument (FEI, Hillsboro, OR, USA) was applied. To carry out these analyses, resultant NFs were diluted 10-fold, placed onto a $\mathrm{Cu}$ grid (CF $400 \mathrm{Cu}-\mathrm{UL}$, Electron Microscopy Sciences, Hatfield, PA, USA), and evaporated under ambient air. After that, the $\mathrm{Cu}$ grid was placed in a TEM chamber. Size and shape distributions of AuNPs were assessed on the basis of 65 single NPs.

XRD was used to estimate the crystalline structure of AuNPs synthesized under optimal conditions. Measurements were performed in the symmetric $\Theta / 2 \Theta$ Bragg-Brentano geometry, using a X-Pert Pro MPD diffractometer (Malvern Panalytical, Malvern, UK) equipped with a CuK $\alpha$ radiation source $(\lambda=0.15406 \mathrm{~nm})$. They were carried out after placing resultant NFs onto a poly(methylmetacrylate) holder and left to dry in ambient air.

\subsection{Qualitative Analyses of Chemical Compounds in Honey Solutions}

ATR FT-IR spectroscopy was applied for the identification of chemical compounds present in aqueous honeys solutions used for synthesis of AuNPs. ATR FT-IR spectra were acquired in the range from 4000 to $370 \mathrm{~cm}^{-1} .20 \%(w / v)$ aqueous honeys solutions and resultant NFs were analyzed. A Vertex 70v ATR FT-IR spectrophotometer (Bruker, Bremen, Germany) equipped with a diamond ATR cell was applied for that purpose.

\subsection{Quantitative Analyses of the Reducing Sugars and Phenolic Compounds Contained in Aqueous Honey Solutions}

The Bertrand method was applied to determine amounts of reducing sugars in honey solutions following description given in references [54,55]. Briefly, $2 \mathrm{~mL}$ of a given $1 \%(w / v)$ honey solution was mixed with $20 \mathrm{~mL}$ of the Bertrand's I solution and $20 \mathrm{~mL}$ of the Bertrand's II solution. Then, the resultant mixture was boiled for $4 \mathrm{~min}$, and then cooled down under cold tap water. The $\mathrm{Cu}_{2} \mathrm{O}$ precipitation formed was washed several times with warm re-distilled water by decanting over a Pyre ${ }^{\circledR}$ Gooch crucible (Sigma-Aldrich, Steinheim, Germany). In the next step, washed $\mathrm{Cu}_{2} \mathrm{O}$ was treated with $20 \mathrm{~mL}$ of the Bertrand's III solution. The resultant solution was immediately titrated by a titrating $\mathrm{KMnO}_{4}$ solution. Titration was carried out until the titrated solution turned to bright pink. One $\mathrm{mL}$ of the titrating $\mathrm{KMnO}_{4}$ solution is associated with $6.537 \mathrm{~g}$ of reduced $\mathrm{Cu}$ (II) ions [55]. The amount of reducing sugars in honeys solution was calculated as follows: reducing sugars (in $\mathrm{mg}$ ) $=0.564 \times$ reduced $\mathrm{Cu}(\mathrm{II})$ ions $(\mathrm{mg})$.

The Folin-Ciocalteu assay was used to assess the concentration of phenolic compounds before and after the addition of $\mathrm{Au}$ (III) ions into the given honey solutions [55]. Briefly, $2.5 \mathrm{~mL}$ of a 10-fold diluted solution of the Folin-Ciocalteu reagent was mixed with a $0.5 \mathrm{~mL}$ of a given $20 \%(w / v)$ honey solution. The so-prepared solution was incubated for $15 \mathrm{~min}$ at $50^{\circ} \mathrm{C}$. After $15 \mathrm{~min}$, it was cooled down in an ice bath for $4 \mathrm{~min}$. Next, absorbance related to the phosphotungstic-phosphotomolybdenium complex formed was measured at $765 \mathrm{~nm}$ using a Specord 210 Plus spectrophotometer (Analytik 
Jena AG, Jena, Germany). To zero the instrument, re-distilled water was applied. Results associated with the concentration of phenolic compounds in analyzed aqueous honey solutions were expressed as gallic acid equivalents (GAE) and given in mg of GAE per L. The calibration curve for GA was acquired within the concentration range of 10 to $150 \mathrm{mg} \cdot \mathrm{L}^{-1}$, treating all standard solutions following the above-described procedure.

\subsection{Thermal Behaviour of AuNPs in a Microwave Radiation Field}

AuNPs synthesized with the aid of the selected honey solution were purified using dialysis tubing cellulose membranes (molecular weight cut-off 14 kDa, Sigma Aldrich, Steinheim, Germany). There was $10 \mathrm{~mL}$ of the so-obtained NF transferred into a $20 \mathrm{~mL}$ volumetric flask and 2-fold diluted with re-distilled water. Afterwards, this solution was introduced into a glass tubular reactor and placed in an ERTEC, model 02-02 microwave reactor (Ertec, Wroclaw, Poland). The procedure of heating was experimentally developed so as to heat the AuNPs-containing NF to $45{ }^{\circ} \mathrm{C}$ within 6 min. Then, temperature was maintained for another $4 \mathrm{~min}$, applying a power of $15 \mathrm{~W}$. The experiment was also carried out under the same conditions, but using water as a control. Temperature of each liquid was monitored every second and the heating rate was calculated using the simplified Newton's law of heating, i.e., $\mathrm{dT}(t) / \mathrm{d} t=\mathrm{k}(\mathrm{h}) \cdot \Delta \mathrm{T}(t)$, where $\mathrm{T}(t)$ is temperature at a given time; $\mathrm{k}(\mathrm{h})$ is the heating rate $\left(\mathrm{s}^{-1}\right)$, and $\Delta \mathrm{T}(t)$ is a difference in temperature over time $t$ [56].

\section{Results and Discussion}

\subsection{Visual Observations of AuNPs Formation Followed by Determination of AuNPs Optical and Granulometric Properties}

As compared to the yellowish colour of AuNPs precursor solutions, colloidal suspensions of AuNPs exhibit a ruby-red colour [55]. For that reason, the first indication that AuNPs were fruitfully synthesized with the aid of honey solutions was the change of colour of the mixed solutions from yellowish (before addition of a solution of $\mathrm{Au}(\mathrm{III})$ ions to a given honey solution) to ruby-red (after addition of the solution of $\mathrm{Au}(\mathrm{III})$ ions). Appearance of such a ruby-red colour in the mixed solution containing $\mathrm{Au}(\mathrm{III})$ ions at $100 \mathrm{mg} \cdot \mathrm{L}^{-1}$ and $20 \%(w / v)$ of honeydew honey was observed after $5 \mathrm{~min}$. On the other hand, for a lime tree honey and multi-flower honey, the mentioned ruby-red colour appeared after 30 and $35 \mathrm{~min}$, respectively, for the mixed solution consisting $100 \mathrm{mg} \cdot \mathrm{L}^{-1} \mathrm{of} \mathrm{Au}(\mathrm{III})$ ions and $20 \%(w / v)$ of honeys. In addition, it was noted that the formation of AuNPs, emanated by the appearance of the ruby-red colour of mixed solutions, strongly depended on the type of honey used for synthesis, as well as the concentration of honey, and the concentration of $\mathrm{Au}(\mathrm{III})$ ions in resultant mixed solutions. Accordingly, differences observed in time after which the ruby-red colour appeared in mixed solutions were directly related to differences in the concentration of chemical compounds, namely reducing sugars and polyphenols, that were responsible for the reduction of $\mathrm{Au}(\mathrm{III})$ ions and the stabilization of AuNPs formed in these conditions [43].

$\mathrm{UV} /$ Vis absorption spectrophotometry was applied to corroborate all visual observations, and to assess optical and granulometric properties of resultant AuNPs. Localized surface resonance of plasmonic AuNPs was responsible for their optical properties in visible light [57]. For colloidal suspension of AuNPs, the absorption band of their localized surface plasmon resonance (LSPR) is situated in the range from 520 to $550 \mathrm{~nm}$ [58]. Furthermore, as the size of AuNPs increases, the position of the LSPR absorption band shifts towards longer wavelengths, absorbing red light and reflecting blue light, as described by the Mie's scattering theory [59].

As shown in Figure 2, the LSPR absorption band was identified in UV/Vis absorption spectra of all of mixed solutions. Hence, on the basis of values on the LSPR absorption band $\lambda_{\max }$, it was possible to select optimal conditions for the production of the smallest in size AuNPs (Figure 2). Accordingly, the lowest value of the LSPR absorption band $\lambda_{\max }$ was $538.5 \mathrm{~nm}$ and was observed for conditions when the lime tree honey solution was used and its final concentration in the mixed solution was $20 \%(w / v)$ 
while the concentration of $\mathrm{Au}(\mathrm{III})$ ions was $25 \mathrm{mg} \cdot \mathrm{L}^{-1}$. When using multi-flower solutions, similar conditions in reference to concentrations of honey and $\mathrm{Au}(\mathrm{III})$ ions were also found to produce the smallest in size AgNPs with the LSPR absorption band $\lambda_{\max }$ located at $538.2 \mathrm{~nm}$. By contrast, optimal conditions for the synthesis of AuNPs with honeydew honey solutions related to the concentration of honey and $\mathrm{Au}(\mathrm{III})$ in the mixed solution was $5 \%(w / v)$ and $50 \mathrm{mg} \cdot \mathrm{L}^{-1}$, respectively. For all honey solutions used, it was established that when the concentration of $\mathrm{Au}$ (III) ions in the mixed solution increased, the position of the LSPR absorption band $\lambda_{\max }$ also increased, indicating that the AuNPs higher in size were formed in these conditions (see results in Table 1). Therefore, for all subsequent experiments, AgNPs were synthesized mixing solutions of honeys and Au(III) ions so as their final concentrations in mixed solutions were $20 \%(w / v)$ and $25 \mathrm{mg} \cdot \mathrm{L}^{-1}$, respectively. Although these latter conditions were not optimal for honeydew honey, they were applied for consistency with conditions established for two other honeys (lime tree, multi-flower).
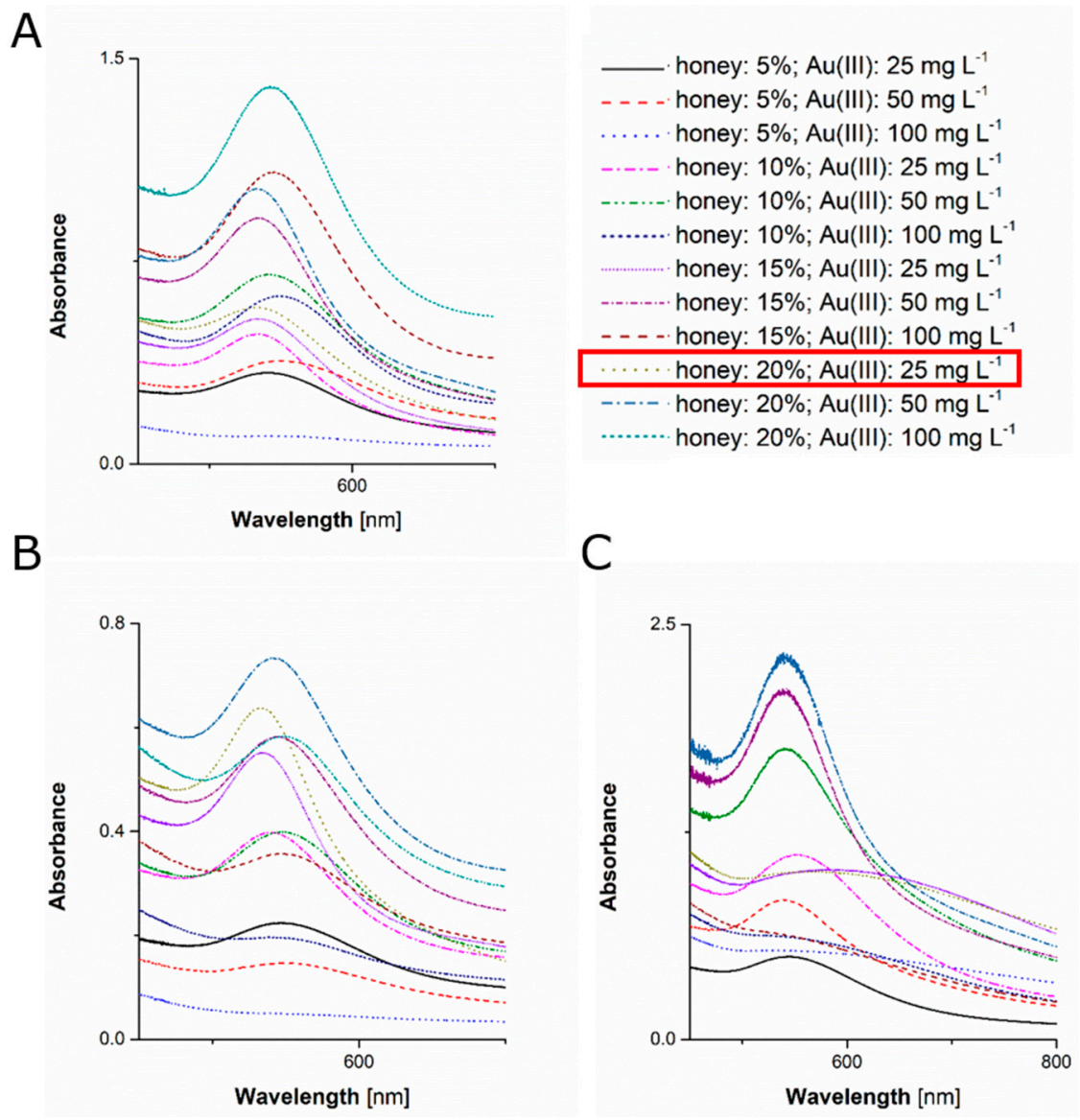

Figure 2. UV/Vis absorption spectra of solutions resulted from mixing solutions of (A) lime tree honey, (B) multiflower honey, and (C) honeydew honey with solutions of Au(III) for green synthesis of AuNPs. The red box indicates pattern of samples subjected to further analytical procedures. 
Table 1. Wavelengths of localized surface plasmon resonance (LSPR) absorption band at its maximum $\left(\lambda_{\max }\right)$ and their absorbances $(\mathrm{A})$ for AuNPs produced under different experimental conditions.

\begin{tabular}{|c|c|c|c|c|c|}
\hline No. & Type of Honey & Honey Concentration (\%) & $\begin{array}{l}\text { Au(III) Concentration } \\
\left(\mathrm{mg} \cdot \mathrm{L}^{-1}\right)\end{array}$ & $\lambda_{\max }(\mathrm{nm})$ & $\mathbf{A}$ \\
\hline 1 & Lime tree & 20 & 100 & 563.4 & 0.17 \\
\hline 2 & Lime tree & 20 & 50 & 550.4 & 0.55 \\
\hline 3 & Lime tree & 20 & 25 & 538.5 & 0.43 \\
\hline 4 & Lime tree & 15 & 100 & 552.5 & 0.45 \\
\hline 5 & Lime tree & 15 & 50 & 543.2 & 0.38 \\
\hline 6 & Lime tree & 15 & 25 & 540.2 & 0.21 \\
\hline 7 & Lime tree & 10 & 100 & 558.1 & 0.27 \\
\hline 8 & Lime tree & 10 & 50 & 551.4 & 0.26 \\
\hline 9 & Lime tree & 10 & 25 & 539.5 & 0.20 \\
\hline 10 & Lime tree & 5 & 100 & 565.2 & 0.02 \\
\hline 11 & Lime tree & 5 & 50 & 561.9 & 0.13 \\
\hline 12 & Lime tree & 5 & 25 & 550.5 & 0.12 \\
\hline 13 & Multiflower & 20 & 100 & 558.3 & 0.15 \\
\hline 14 & Multiflower & 20 & 50 & 550.3 & 0.23 \\
\hline 15 & Multiflower & 20 & 25 & 538.3 & 0.25 \\
\hline 16 & Multiflower & 15 & 100 & 559.1 & 0.08 \\
\hline 17 & Multiflower & 15 & 50 & 553.1 & 0.20 \\
\hline 18 & Multiflower & 15 & 25 & 538.5 & 0.21 \\
\hline 19 & Multiflower & 10 & 100 & 538.4 & 0.25 \\
\hline 20 & Multiflower & 10 & 50 & 559.1 & 0.08 \\
\hline 21 & Multiflower & 10 & 25 & 553.4 & 0.19 \\
\hline 22 & Multiflower & 5 & 100 & 561.4 & 0.02 \\
\hline 23 & Multiflower & 5 & 50 & 557.2 & 0.13 \\
\hline 24 & Multiflower & 5 & 25 & 547.9 & 0.14 \\
\hline 25 & Honeydew & 20 & 100 & 569.6 & 0.01 \\
\hline 26 & Honeydew & 20 & 50 & 558.2 & 0.07 \\
\hline 27 & Honeydew & 20 & 25 & 550.2 & 0.90 \\
\hline 28 & Honeydew & 15 & 100 & 654.1 & 0.16 \\
\hline 29 & Honeydew & 15 & 50 & 576.9 & 0.04 \\
\hline 30 & Honeydew & 15 & 25 & 657.2 & 0.25 \\
\hline 31 & Honeydew & 10 & 100 & 595.1 & 0.06 \\
\hline 32 & Honeydew & 10 & 50 & 553.5 & 0.59 \\
\hline 33 & Honeydew & 10 & 25 & 551.3 & 0.39 \\
\hline 34 & Honeydew & 5 & 100 & 631.8 & 0.04 \\
\hline 35 & Honeydew & 5 & 50 & 540.7 & 0.83 \\
\hline 36 & Honeydew & 5 & 25 & 552.3 & 0.28 \\
\hline
\end{tabular}

\subsection{Morphology of AuNPs Synthesized under Selected Conditions}

TEM was used to assess granulometric properties of AuNPs produced under selected experimental conditions (see Section 3.1 and Figure 2). It was observed that AuNPs synthesized using the lime tree honey solution consisted of aggregated grains (see Figure 3A). A variety of shapes were found, including spherical $(68 \%)$, triangular $(18 \%)$, rod-like $(5 \%)$, trapezoidal $(3 \%)$, star-like $(1 \%)$, and polyhedral (5\%). Average size of all these AuNPs was $51.6 \pm 84.4 \mathrm{~nm}$. AuNPs produced using the multiflower honey solution were well dispersed, uniform in size, and non-aggregated (Figure 3B). Again, a variety of shapes, including spherical (77\%), triangular (17\%), polyhedral (2\%), trapezoidal $(2 \%)$, hexagonal $(1 \%)$, and rod-like $(1 \%)$, were observed for these AuNPs. Their average size was $20.6 \pm 23.3 \mathrm{~nm}$ and was lower as compared to the average size of Au nanostructures produced with the aid of the lime tree honey solution. Finally, Au nanostructures synthesized using the honeydew honey solution were well dispersed and non-aggregated as well (Figure 3C). Their average size was $25.1 \pm 26.3 \mathrm{~nm}$, which was lower as compared to Au nanostructures produced with the aid of the lime tree honey solution, and similar to this obtained with the multiflower honey solution. For honeydew 
honey, most of AuNPs were spherical (80\%), but other shapes, i.e., triangular (2\%), polyhedral $(17 \%)$, and rod-like (1\%), were found as well.
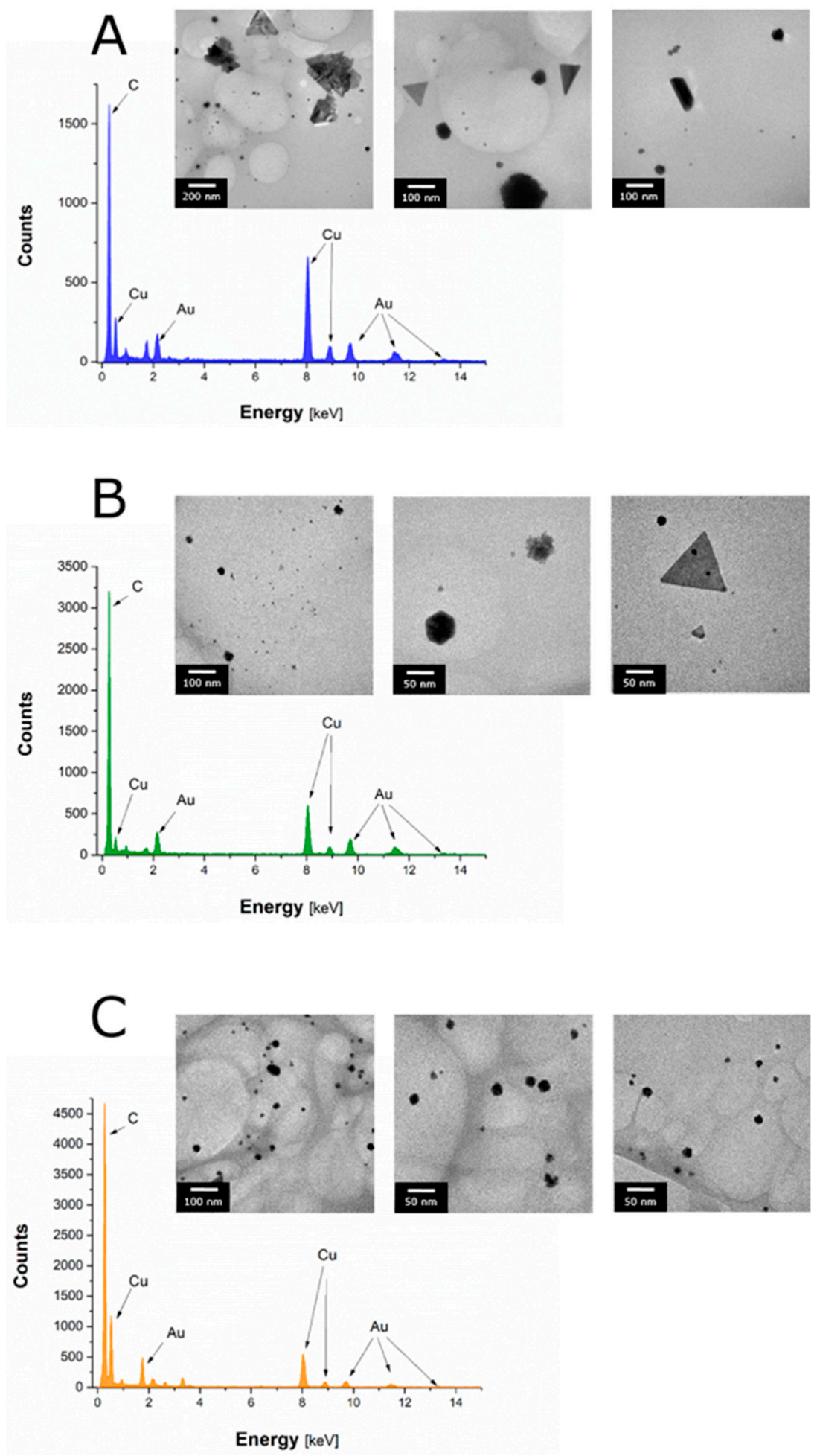

Figure 3. Transmission electron microscopy (TEM) photomicrographs and energy-dispersive X-ray spectroscopy (EDX) spectra of AuNPs produced with the aid of (A) lime tree honey, (B) multiflower honey, and $(\mathbf{C})$ honeydew honey solutions.

EDX was applied to confirm the elemental composition of synthesized AuNPs (Figure 3). As expected, peaks corresponding to $\mathrm{Au}, \mathrm{C}$, and $\mathrm{Cu}$ (from the $\mathrm{Cu}$ grid onto which NFs were placed) 
were identified in all NFs (Figure 3A-C), confirming AuNPs presence through green synthesis with honey solutions.

XRD was used to determine the crystalline structure of AuNPs produced with the aid of solutions of multiflower and honeydew honeys (Figure 4). In the case of the lime tree honey solution, such analysis was not possible, as the efficiency of AuNPs synthesis appeared to be too low to collect a sufficient amount of dry material. As can be seen in Figure 4, diffraction peaks in diffractograms of analyzed NFs containing AuNPs are situated at 38.1, 44.4, and $64.5^{\circ}(2 \theta)$. Those peaks corresponded to Miller's indices (111), (200), and (220), respectively, which are intrinsic for the face-centered cubic (fcc) crystalline structure for Au.

A

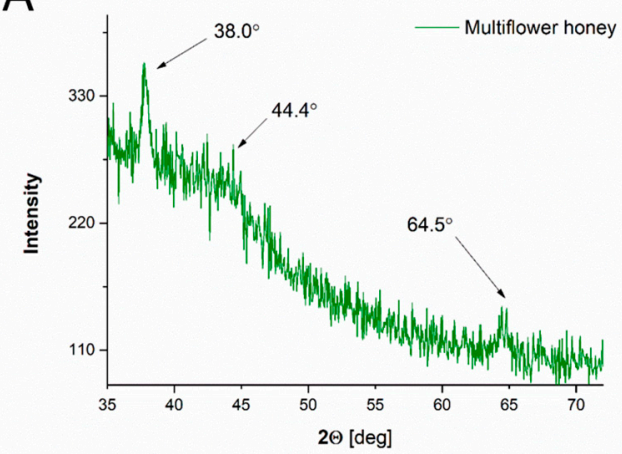

B

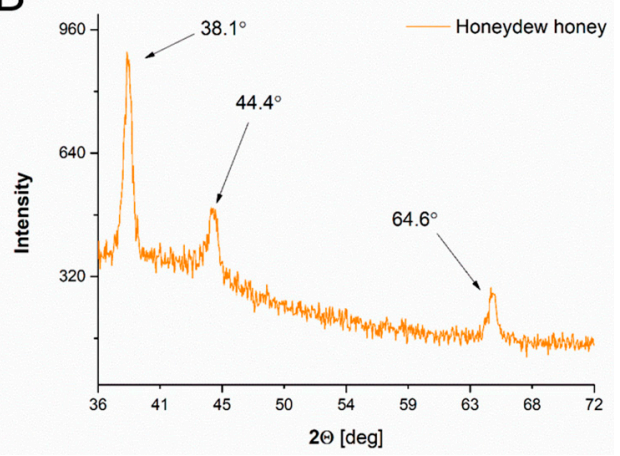

Figure 4. XRD patterns of AuNPs produced by using (A) multiflower honey and (B) honeydew honey solutions.

To compare the average size of crystalline AuNPs evaluated using TEM and XRD, the Scherrer equation was used. For AuNPs produced with the multiflower honey solution or with the honeydew honey solution, this equation was applied to the width of the most intense diffraction peak in the XRD pattern, i.e., the one with (111) Miller's indices. Accordingly, it was established that the average size of Au nanostructures produced using the multiflower honey solution was $18.0 \mathrm{~nm}$. In the case of the honeydew honey solution it was $12.2 \mathrm{~nm}$. The average size of AuNPs estimated by TEM was about twice higher than the average size estimated on the basis of XRD measurements. This obvious divergence is reported in literature and attributed to the fact that XRD provides the distribution of the average size of NPs in terms of their volume, while TEM gives distribution of average size by their number [60]. When the number size distribution is calculated, each particle has equal weighting, while the volume size distribution recognizes the average size of the NPs revealing the greatest total volume.

\subsection{Qualitative Analyses of Chemical Compounds Present in Mixed Solutions}

ATR FT-IR spectroscopy was used to identify chemical compounds present in honey solutions as well as in mixed solutions (Figure 5). Considering ATR FT-IR spectra of honey solutions, the most intense bands (around $3270 \mathrm{~cm}^{-1}$ ) were related to stretching vibrations $v$ of the $-\mathrm{OH}$ group, originating from water molecules (Figure 5). Occurrence of bands at $2930 \mathrm{~cm}^{-1}$ was associated with stretching vibrations $v$ of the $\mathrm{C}-\mathrm{H}$ group, or with stretching vibrations $v$ of the $\mathrm{N}-\mathrm{H}$ group [61]. Mentioned stretching vibrations $v$ might have originated from carboxylic acids or from free amino acids, respectively, present in all analyzed honey solutions [61]. Furthermore, bending vibrations $\delta$ of the $\mathrm{O}-\mathrm{CH}$ group (range 1342-1418 $\mathrm{cm}^{-1}$ ) were related to carbohydrate compounds like glucose and D-fructose, also occurring in analyzed honey solutions [61]. In addition, the presence of proteins was confirmed by intense peaks (range 1450-1240 $\mathrm{cm}^{-1}$ ), related to stretching vibrations $v$ of the C-N group (the amide III band), and in-plane bending vibrations $\delta$ of the $\mathrm{N}-\mathrm{H}$ group (the amide II band). Moreover, proteins were identified due to the occurrence of $\mathrm{C}-\mathrm{O}-\mathrm{C}$ symmetric stretching vibrations $v$ and $\mathrm{C}-\mathrm{O}-\mathrm{H}$ bending vibrations $\delta$ (around $1026 \mathrm{~cm}^{-1}$ ) of the $-\mathrm{C}=\mathrm{O}$ group [42]. 
A

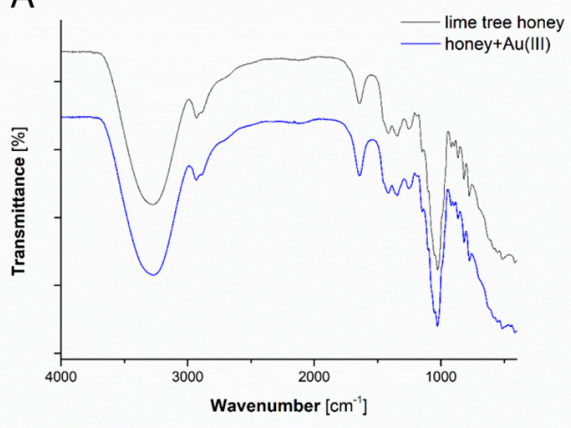

B

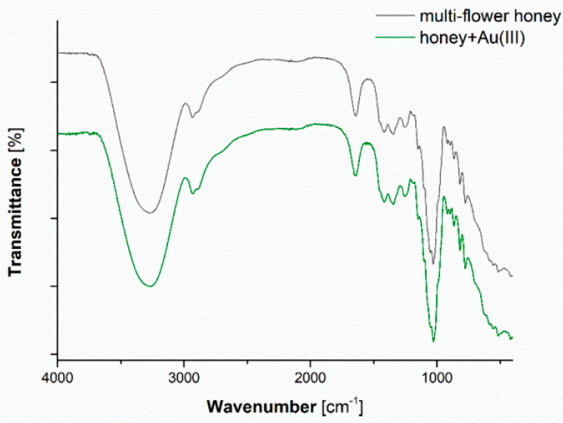

C

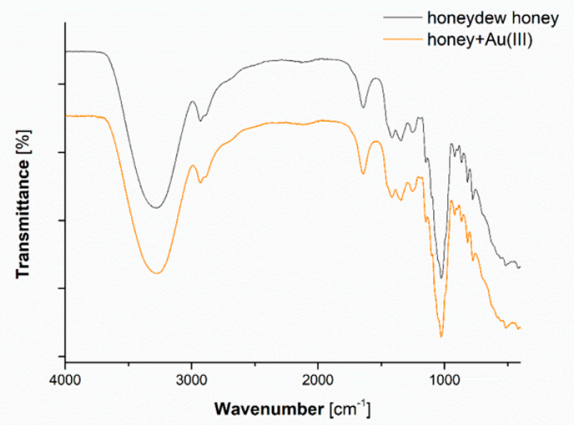

Figure 5. Attenuated total reflectance Fourier transform-infrared spectroscopy (ATR FT-IR) spectra acquired for honey solutions as well as for mixed solutions containing AuNPs that were produced with the aid of (A) lime tree honey, (B) multiflower honey, and (C) honeydew honey solutions.

ATR FT-IR spectra of mixed solutions containing AuNPs, produced using given honey solutions, were very similar to those recorded for aqueous honey solutions (Figure 5). However, the identified bands were slightly shifted towards longer wavelengths in case of mixed solutions containing synthesised AuNPs. Those shifts in wavelengths of vibration bands might suggest that carboxylic acids, free amino-acids, monosaccharaides (glucose, D-fructose), and proteins present in honey solutions could be responsible for the stabilization of resultant AuNPs [42].

\subsection{Quantitative Analyses of Reducing Sugars and Phenolic Compounds Contained in Honeys}

Several studies demonstrate that reducing sugars and phenolic compounds play a significant role in green synthesis of AuNPs [28,33,55]. Their contribution to the formation of AuNPs is likely associated with their reducing and stabilizing properties [55]. For that reason, the concentration of reducing sugars and phenolic compounds in honey solutions used for green synthesis of AuNPs, before and after the addition of a solution of $\mathrm{Au}(\mathrm{III})$ ions into them, have been examined. It was found that the concentration of reducing sugars and phenolic compounds in honey solutions changed after the addition of $\mathrm{Au}(\mathrm{III})$ ions (Table 2). This suggested that these compounds were involved in the production of $\mathrm{Au}$ nanostructures. In addition, a relationship between the concentration of reducing sugars in honey solutions and the average size of produced AuNPs was found (Table 2, Figure 6). Honey solutions with high total concentrations of reducing sugars seemingly led to formation of smaller in size AuNPs. As was suggested by Snitka et al. [43], honey-mediated formation of AuNPs was related to the total concentration of reducing sugars, as well as to the type of reducing sugars. Apparently from the cited work, glucose (aldose) was found to be the main reducing agent in green synthesis of AuNPs, and this was associated with the presence of the aldehyde group [43]. On the other hand, D-fructose (ketose) exhibited only stabilizing properties during synthesis of AuNPs [43]. Stabilizing properties of D-fructose were related to repulsive forces (electrostatic or steric) due to its hydrophobic carbon chain. Overall, Snitka et al. suggested that glucose was a primary compound involved in 
honey-mediated reduction of $\mathrm{Au}(\mathrm{III})$ to $\mathrm{Au}^{0}$ of nanometric size, whereas D-fructose behaved as a capping agent for AuNPs nucleation and their growth, and prevented their aggregation [43]. However, no correlation between the total content of phenolics and size of resultant AuNPs was found (Table 2). Thus, it was concluded that reducing sugars were crucial for determining the size of resultant AuNPs.

Table 2. Total concentration of reducing sugars (in $\mathrm{mg} \cdot \mathrm{mL}^{-1}$ ) and phenolic compounds (expressed as a gallic acid equivalent in $\mathrm{mg} \cdot \mathrm{L}^{-1}$ ) determined in undiluted honeys before and after addition of $\mathrm{Au}(\mathrm{III})$ ions for AuNPs synthesis.

\begin{tabular}{cccccc}
\hline \multirow{2}{*}{ Honey } & \multicolumn{2}{c}{$\begin{array}{c}\text { Before } \\
\text { Addition of Au(III) }\end{array}$} & \multicolumn{2}{c}{$\begin{array}{c}\text { After } \\
\text { Addition of Au(III) }\end{array}$} & \multirow{2}{*}{$\begin{array}{c}\text { AuNPs Mean } \\
\text { Size (nm) }\end{array}$} \\
\cline { 2 - 5 } & Reducing Sugars & Polyphenols & Reducing Sugars & Polyphenols & \\
\hline Lime tree & 620.7 & 65.97 & 515.0 & 56.29 & $51.6 \pm 84.4$ \\
Multiflower & 780.2 & 41.61 & 569.6 & 35.46 & $20.6 \pm 23.3$ \\
Honeydew & 889.5 & 145.4 & 493.1 & 104.7 & $25.1 \pm 26.3$ \\
\hline
\end{tabular}

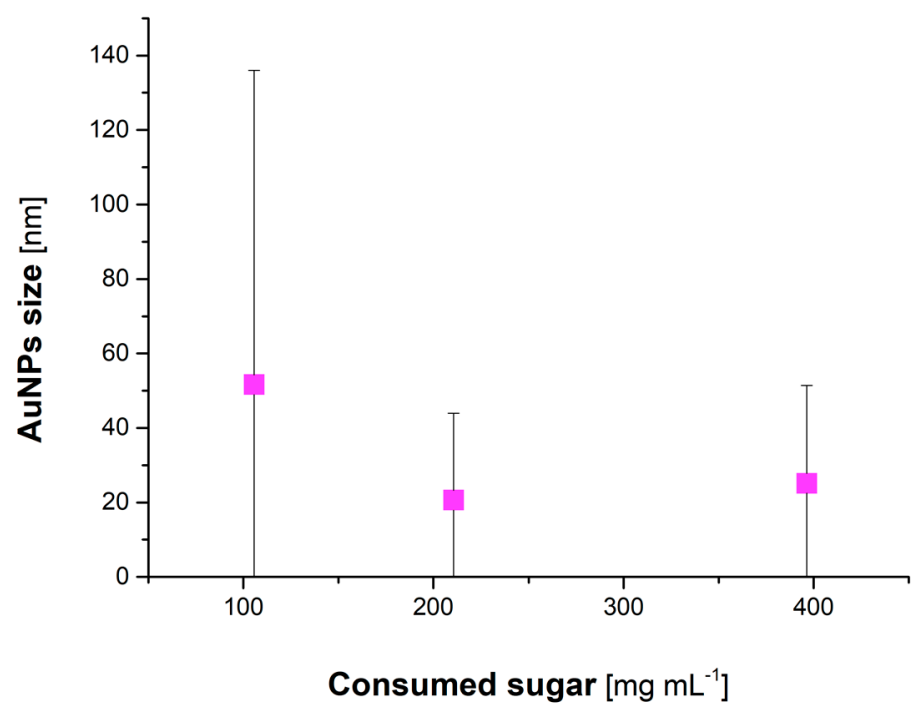

Figure 6. Relationship between the AuNPs size and the concentration of consumed reducing sugars $\left(\mathrm{mg} \cdot \mathrm{mL}^{-1}\right)$.

\subsection{Application of AuNPs in Microwave-Induced Hyperthermia}

Microwave-thermal behaviour of AuNPs obtained with the aid of multiflower and honeydew honeys was tested. Those nanostructures were characterized by the smallest average size, i.e., $\sim 20-25 \mathrm{~nm}$ (see Figure 3C). Hence, it was expected that those AuNPs would be the most susceptible to excitation by a microwave radiation field. The obtained data for AuNPs produced with solutions of both mentioned honeys were very similar; therefore, only slight differences between each other were expected.

In Figure 7, heating curves of water and these recorded for the NF containing AuNPs obtained with the aid of both honeys are shown. As can be seen, AuNPs synthesized using multiflower honey were heated to $45^{\circ} \mathrm{C}$ in about $5 \mathrm{~min}$. Meanwhile, the AuNPs fabricated in the solution of honeydew honey reached maximum of $44^{\circ} \mathrm{C}$ in about $6 \mathrm{~min}$. The differences are attributed to the slightly greater average size of the latter ones, leading to the conclusion, that greater area-to-surface ratio ensures more effective heating. In the same time, exposure to microwaves (at $15 \mathrm{~W}$ ) led water to be heated up to $30{ }^{\circ} \mathrm{C}$, however, the system needed almost $7 \mathrm{~min}$ to achieve this. As a result, the greatest heating rate to maximum temperature was recorded for the medium with AuNPs obtained with the aid of multiflower honey $\left(11.7 \times 10^{-3} \mathrm{~s}^{-1}\right)$ as compared to this for water $\left(6.8 \times 10^{-3} \mathrm{~s}^{-1}\right)$. Since the tested NFs with AuNPs was heated to temperatures $14-15^{\circ} \mathrm{C}$ greater than the temperature of water, it could 
be stated that AuNPs indeed might be applicable in hyperthermia treatment procedures. To maintain constant temperature of the NF containing AuNPs required the microwave field to be periodically turned off and turned on. No such operation was required for water, which was constantly exposed to microwave radiation. It must be remembered that in real life conditions, both AuNPs and water in tissues would be heated at the same time by exactly the same exposure to microwaves, whether it would be turned off or turned on. Hence, maintaining constant hyperthermia of AuNPs would inevitably lead to cyclic turning off microwave radiation. This in turn would result in a decrease of temperature of surrounding tissues. Therefore, based on the observed phenomena, and due to the fact that Au nanostructures produced with the aid of honey solutions were likely functionalized by monosaccharaides such as glucose and D-fructose, it could be stated that such green synthesized AuNPs would be suitable for microwave hyperthermia treatment of cancer.

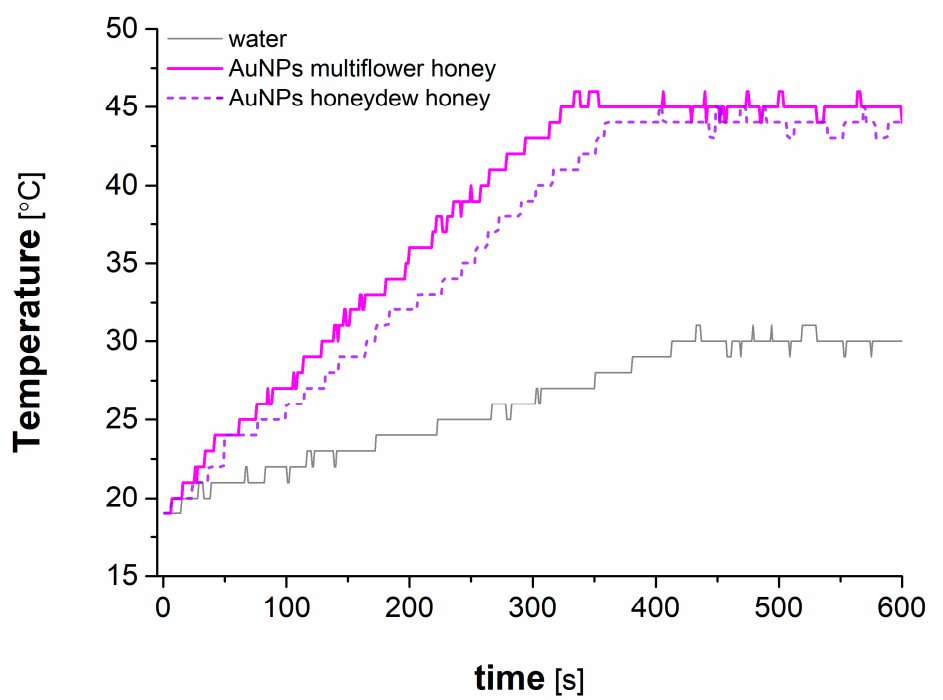

Figure 7. Microwave-induced heating curves recorded for water and the nanofluid containing AuNPs obtained with the aid of a multiflower honey solution.

\section{Conclusions}

Three types of commercially available Polish honeys were applied for size-defined green synthesis of NFs containing AuNPs. By selecting the type of honey, and the concentration of honey and $\mathrm{Au}(\mathrm{III})$ ions in mixed solutions, appropriate experimental conditions mediating green synthesis of the smallest in size Au nanostructures were found. Based on UV/Vis and TEM measurements, the smallest in size AuNPs were efficiently produced when the concentration of honeydew honey and $\mathrm{Au}(\mathrm{III})$ ions in the mixed solution was $20 \%(w / v)$ and $25 \mathrm{mg} \cdot \mathrm{L}^{-1}$, respectively. Resultant Au nanostructures were mostly spherical in shape $(\sim 80 \%)$ and exhibited the average size of $20.6 \pm 23.3 \mathrm{~nm}$, as assessed by TEM. Elemental composition of so-prepared AuNPs was determined by EDX, while their crystalline structure was established using XRD. It was confirmed that AuNPs were formed with the face-centered cubic crystalline structure. In addition, it was established that NFs containing AuNPs produced by this simple and fast green synthesis method developed here might be useful in microwave-induced hyperthermia treatment of cancer. To reveal the role of chemical compounds present in honey solutions used for synthesis, qualitative and quantitative analyses of chemical compounds likely involved in AuNPs production were carried out. Based on ATR FT-IR measurements, it was suggested that carboxylic acids, free amino-acids, monosaccharaides (glucose, D-fructose), and proteins might be involved in capping and functionalization of produced nanostructures. In addition, it was noted that reducing sugars as well as polyphenolic compounds played a crucial role in AuNPs formation.

Author Contributions: A.D. and P.C. planned all experiments related to green synthesis of AuNPs and their application in microwave-induced activity for hyperthermia treatment of cancer. A.D. and M.R. carried out 
all AuNPs fabrications. P.J., A.C., M.R. and A.D. determined optical properties of resultant AuNPs. A.D. and M.R. assessed granulometric properties of obtained AuNPs. A.D. and M.R. carried out quantitative analyses of reducing sugars and phenolic compounds in applied honeys solutions. P.C. and D.J.-B. performed measurements associated with microwave excitation of AuNPs. A.D. and P.C. summarized all data and wrote the manuscript. P.J., D.J.-B., and P.P. supervised all work and took part in discussion.

Funding: This work was financed by a statutory activity subsidy from the Polish Ministry of Science and Higher Education for the Faculty of Chemistry of Wroclaw University of Science and Technology (nos. 0401/0120/18 and 0401/0126/18). Anna Dzimitrowicz is supported by the Foundation for Polish Science (FNP), program START 022.2018 .

Acknowledgments: Authors would like to thank Anna Lesniewicz and to Dorota Pogoda from Wroclaw University of Science and Technology for acquiring XRD diffractograms and ATR FT-IR spectra, respectively.

Conflicts of Interest: The authors declare no conflict of interest.

\section{References}

1. Ray, P.C.; Yu, H.; Fu, P.P. Toxicity and environmental risks of nanomaterials challenges and future needs. J. Environ. Sci. Health C. Environ. Carcinog. Ecotoxicol. Rev. 2009, 27, 1. [CrossRef]

2. Biener, J.; Wittstock, A.; Baumann, T.; Weissmuller, J.; Baumer, M.; Hamza, A. Surface chemistry in nanoscale materials. Materials 2009, 2, 2404. [CrossRef]

3. Kelsall, R.W.; Hamley, I.W.; Geoghegan, M. Nanoscale Science and Technology; John Wiley and Sons Ltd.: West Sussex, UK, 2008.

4. Ricciardi, L.; Sancey, L.; Palermo, G.; Termine, R.; De Luca, A.; Szerb, E.I.; Aiello, I.; Ghedini, M.; Strangi, G.; La Deda, M. Plasmon-mediated cancer phototherapy: The combined effect of thermal and photodynamic processes. Nanoscale 2017, 9, 19279. [CrossRef] [PubMed]

5. Pezzi, L.; Palermo, G.; Veltri, A.; Cataldi, U.; Burgi, T.; Ritacco, T.; De Luca, A. Photo-thermal study of a layer of randomly distributed gold nanoparticles: From nano-localization to macro-scale effects. J. Phys. D. 2017, 50, 435302. [CrossRef]

6. Palermo, G.; Ritacco, T.; Aceti, D.; Pezzi, L.; Giocondo, M.; De Luca, A. Photo-thermal effects in 1D gratings of gold nanoparticles. Crystals 2017, 7, 14. [CrossRef]

7. Palermo, G.; Pagnotto, D.; Ricciardi, L.; Pezzi, L.; La Deda, M.; De Luca, A. Thermoplasmonic Effects in Gain-Assisted Nanoparticle Solutions. J. Phys. Chem. C 2017, 121, 24185. [CrossRef]

8. Huang, D.; Liao, F.; Molesa, S.; Redinger, D.; Subramanian, V. Plastic-compatible low resistance printable gold nanoparticle conductors for flexible electronics. J. Electrochem. Soc. 2003, 150, G412. [CrossRef]

9. Prasad, B.L.V.; Stoeva, S.I.; Sorensen, C.M.; Zaikovski, V.; Klabunde, K.J. Gold nanoparticles as catalysts for polymerization of alkylsilanes to siloxane nanowires, filaments, and tubes. J. Am. Chem. Soc. 2003, 125, 10488. [CrossRef]

10. Draz, M.S.; Shafieem, H. Applications of gold nanoparticles in virus detection. Theranostics 2018, 8, 1985. [CrossRef]

11. Cole, L.E.; Ross, R.D.; Tilley, J.M.; Vargo-Gogola, T.; Roeder, R.K. Gold nanoparticles as contrast agents in x-ray imaging and computed tomography. Nanomedicine 2015, 10, 321. [CrossRef]

12. Sparkling, R.A.; Gil, P.R.; Zhang, F.; Zanella, M.; Parak, W.J. Biological applications of gold nanoparticles. Chem. Soc. Rev. 2008, 37, 1896. [CrossRef] [PubMed]

13. Huang, H.; Jain, P.; El-Sayed, I.; El-Sayed, M. Plasmonic photothermal therapy (PPTT) using gold nanoparticles. Lasers. Med. Sci. 2008, 23, 217. [CrossRef]

14. Van der Heijden, A.G.; Kiemeney, L.A.; Gofrit, O.N.; Nativ, O.; Sidi, A.; Leib, Z.; Colombo, R.; Naspro, R.; Pavone, M.; Baniel, J.; et al. Preliminary european results of local microwave hyperthermia and chemotherapy treatment in intermediate or high risk superficial transitional cell carcinoma of the bladder. Eur. Urol. 2004, 46, 65. [CrossRef] [PubMed]

15. Burfeindt, M.J.; Zastrow, E.; Hagness, S.C.; Van Veen, B.D.; Medow, J.E. Microwave beamforming for non-invasive patient-specific hyperthermia treatment of pediatric brain cancer. Phys. Med. Biol. 2011, 56, 2743. [CrossRef]

16. Matsumine, A.; Takegami, K.; Asanuma, K.; Matsubara, T.; Nakamura, T.; Uchida, A.; Sudo, A. A novel hyperthermia treatment for bone metastases using magnetic materials. Int. J. Clin. Oncol. 2011, 16, 101. [CrossRef] [PubMed] 
17. Zastrow, E.; Hagness, S.C.; Van Veen, B.D. 3d computational study of non-invasive patient-specific microwave hyperthermia treatment of breast cancer. Phys. Med. Biol. 2010, 55, 3611. [CrossRef]

18. Converse, M.; Bond, E.J.; Veen, B.; Hagness, C. A computational study of ultra-wideband versus narrowband microwave hyperthermia for breast cancer treatment. IEEE Trans. Microwave Theory Tech. 2006, 54, 2169. [CrossRef]

19. Nguyen, P.T.; Abbosh, A.M.; Crozier, S. 3-d focused microwave hyperthermia for breast cancer treatment with experimental validation. IEEE Trans. Antennas Propag. 2017, 65, 3489. [CrossRef]

20. Martin, G.T.; Haddad, M.G.; Cravalho, E.G.; Bowman, H.F. Thermal model for the local microwave hyperthermia treatment of benign prostatic hyperplasia. IEEE Trans. Biomed. Eng. 1992, 39, 836. [CrossRef]

21. Seki, T.; Wakabayashi, M.; Nakagawa, T.; Imamura, M.; Tamai, T.; Nishimura, A.; Yamashiki, N.; Okamura, A.; Inoue, K. Percutaneous microwave coagulation therapy for patients with small hepatocellular carcinoma: Comparison with percutaneous ethanol injection therapy. Cancer Interdiscip. Int. J. Am. Cancer Soc. 1999, 85, 1694. [CrossRef]

22. Svaasand, L.O.; Gomer, C.J.; Morinelli, E. On the physical rationale of laser induced hyperthermia. Lasers Med. Sci. 1990, 5, 121. [CrossRef]

23. Cyganowski, P.; Dzimitrowicz, A.; Jamroz, P.; Jermakowicz-Bartkowiak, D.; Pohl, P. Polymerization-driven immobilization of dc-apgd synthesized gold nanoparticles into a quaternary ammonium-based hydrogel resulting in a polymeric nanocomposite with heat-transfer applications. Polymers 2018, 10, 377. [CrossRef]

24. Dzimitrowicz, A.; Cyganowski, P.; Pohl, P.; Jermakowicz-Bartkowiak, D.; Terefinko, D.; Jamroz, P. Atmospheric pressure plasma-mediated synthesis of platinum nanoparticles stabilized by poly(vinylpyrrolidone) with application in heat management systems for internal combustion chambers. Nanomaterials 2018, 8, 619. [CrossRef] [PubMed]

25. Makarov, V.V.; Love, A.J.; Sinitsyna, O.V.; Makarova, S.S.; Yaminsky, I.V.; Taliansky, M.E.; Kalinina, N.O. "Green" nanotechnologies: Synthesis of metal nanoparticles using plants. Acta Nat. 2014, 6, 35.

26. Celentano, M.; Jakhmola, A.; Profeta, M.; Battista, E.; Guarnieri, D.; Gentile, F.; Netti, P.A.; Vecchione, R. Diffusion limited green synthesis of ultra-small gold nanoparticles at room temperature. Colloids Surf. A Physicochem. Eng. Asp. 2018, 558, 548. [CrossRef]

27. Jakhmola, A.; Celentano, M.; Vecchione, R.; Manikas, A.; Battista, E.; Calcagno, V.; Netti, P.A. Self-assembly of gold nanowire networks into gold foams: Production, ultrastructure and applications. Inorg. Chem. Front. 2017, 4, 1033. [CrossRef]

28. Dzimitrowicz, A.; Jamroz, P.; diCenzo, G.; Sergiel, I.; Kozlecki, T.; Pohl, P. Preparation and characterization of gold nanoparticles prepared with aqueous extracts of Lamiaceae plants and the effect of follow-up treatment with atmospheric pressure glow microdischarge. Arab. J. Chem. 2016. [CrossRef]

29. Ankamwar, B. Biosynthesis of gold nanoparticles (green-gold) using leaves extract of Terminalia catappa. E-J. Chem. 2010, 7, 1334. [CrossRef]

30. Dubey, S.P.; Lahtinen, M.; Sillanpaa, M. Green synthesis and characterizations of silver and gold nanoparticles using leaf extract of Rosa rugosa. Colloids Surf. A Physicochem. Eng. Asp. 2010, 364, 34. [CrossRef]

31. Philip, D. Green synthesis of gold and silver nanoparticles using Hibiscus rosa sinensis. Physica E Low Dimens. Syst. Nanostruct. 2010, 42, 1417. [CrossRef]

32. Huang, J.; Li, Q.; Sun, D.; Lu, Y.; Su, Y.; Yang, X.; Wang, H.; Wang, Y.; Shao, W.; He, N.; Hong, J.; Chen, C. Biosynthesis of silver and gold nanoparticles by novel sundried Cinnamomum camphora leaf. Nanotechnology 2007, 18, 105104. [CrossRef]

33. Dzimitrowicz, A.; Berent, S.; Motyka, A.; Jamroz, P.; Kurcbach, K.; Sledz, W.; Pohl, P. Comparison of the characteristics of gold nanoparticles synthesized using aqueous plant extract and natural plant essential oil of Eucalyptus globulus and Rosmarinus officinalis. Arab. J. Chem. 2016. [CrossRef]

34. Aljabali, A.A.; Akkam, Y.; Al Zoubi, M.S.; Al-Batayneh, K.M.; Al-Trad, B.; Abo Alrob, O.; Alkilany, A.M.; Benamara, M.; Evans, D.J. Synthesis of gold nanoparticles using leaf extract of Ziziphus zizyphus and their antimicrobial activity. Nanomaterials 2018, 8, 174. [CrossRef] [PubMed]

35. Ankamwar, B.; Pansare, S.; Sur, U.K. Centrifuge controlled shape tuning of biosynthesized gold nanoparticles obtained from Plumbago zeylanica leaf extract. J. Nanosci. Nanotechnol. 2017, 17, 1041. [CrossRef] [PubMed]

36. Nadagouda, M.N.; Iyanna, N.; Lalley, J.; Han, C.; Dionysiou, D.D.; Varma, R.S. Synthesis of silver and gold nanoparticles using antioxidants from blackberry, blueberry, pomegranate, and turmeric extracts. ACS Sustain. Chem. Eng. 2014, 2, 1717. [CrossRef] 
37. Sheny, D.S.; Mathew, J.; Philip, D. Synthesis, characterization and catalytic action of hexagonal gold nanoparticles using essential oils extracted from Anacardium occidentale. Spectrochim. Acta A Mol. Biomol. Spectrosc. 2012, 97, 306. [CrossRef] [PubMed]

38. Muniyappan, N.; Nagarajan, N.S. Green synthesis of gold nanoparticles using Curcuma pseudomontana essential oil, its biological activity and cytotoxicity against human ductal breast carcinoma cells T47D. J. Environ. Chem. Eng. 2014, 2, 2037. [CrossRef]

39. Dash, S.S.; Bag, B.G. Synthesis of gold nanoparticles using renewable Punica granatum juice and study of its catalytic activity. Appl. Nanosci. 2014, 4, 55. [CrossRef]

40. Bogireddy, N.K.R.; Gomez, L.M.; Osorio-Roman, I.; Agarwal, V. Synthesis of gold nanoparticles using Coffea Arabica fruit extract. Adv. Nano. Res. 2017, 5, 253.

41. Roy Chowdhury, N.; Cowin, A.; Zilm, P.; Vasilev, K. “Chocolate” gold nanoparticles-One pot synthesis and biocompatibility. Nanomaterials 2018, 8, 496. [CrossRef]

42. Philip, D. Honey-mediated green synthesis of gold nanoparticles. Spectrochim. Acta. A Mol. Biomol. Spectrosc. 2009, 73, 650. [CrossRef]

43. Snitka, V.; Naumenko, D.O.; Ramanauskaite, L.; Kravchenko, S.A.; Snopok, B.A. Generation of diversiform gold nanostructures by honey's components: Growth mechanism, characterization, and shape separation by centrifugation-assisted sedimentation. J. Colloid Interface Sci. 2012, 386, 99. [CrossRef] [PubMed]

44. Sreelakshmi, C.; Datta, K.K.R.; Yadav, J.S.; Reddy, B.V. Honey derivatized Au and Ag nanoparticles and evaluation of its antimicrobial activity. J. Nanosci. Nanotechnol. 2011, 11, 6995. [CrossRef]

45. Ball, D.W. The chemical composition of honey. J. Chem. Edu. 2007, 84, 1643. [CrossRef]

46. Boukraa, L. Honey in Traditional and Modern Medicine; CRC Press: Boca Raton, FL, USA, 2013.

47. Rosenbaum, S. Honey: From Flower to Table; Chronicle Books: San Francisco, CA, USA, 2002.

48. Pohl, P.; Stecka, H.; Sergiel, I.; Jamroz, P. Different aspects of the elemental analysis of honey by flame atomic absorption and emission spectrometry: A review. Food Anal. Methods 2012, 5, 737. [CrossRef]

49. Wang, J.; Kliks, M.M.; Jun, S.; Jackson, M.; Li, Q.X. Rapid analysis of glucose, fructose, sucrose, and maltose in honeys from different geographic regions using Fourier transform infrared spectroscopy and multivariate analysis. J. Food. Sci. 2010, 75, C208. [CrossRef] [PubMed]

50. Mato, I.; Huidobro, J.F.; Simal-Lozano, J.; Sancho, M.T. Rapid determination of nonaromatic organic acids in honey by capillary zone electrophoresis with direct ultraviolet detection. J. Agric. Food Chem. 2006, 54, 1541. [CrossRef] [PubMed]

51. Biesaga, M.; Pyrzynska, K. Stability of bioactive polyphenols from honey during different extraction methods. Food Chem. 2013, 136, 46. [CrossRef] [PubMed]

52. Jerkovic, I.; Kus, P.M. Terpenes in honey: Occurrence, origin and their role as chemical biomarkers. RSC Adv. 2014, 4, 31710. [CrossRef]

53. Castro-Vazquez, L.; Perez-Coello, M.S.; Cabezudo, M.D. Analysis of volatile compounds of rosemary honey. Comparison of different extraction techniques. Chromatographia 2003, 57, 227. [CrossRef]

54. Chidan Kumar, C.S.; Mythily, R.; Venkatachalapathy, R.; Chandraju, S. Bio-mimic conversion of Maida (polysaccharides) to reducing sugars by acid hydrolysis and its estimation using standard methods. Int. Food Res. J. 2014, 21, 523.

55. Dzimitrowicz, A.; Jamroz, P.; Gil, W.; Bojszczak, W.; Motyka, A.; Pogoda, D.; Pohl, P. Fermented juices as reducing and capping agents for the biosynthesis of size-defined spherical gold nanoparticles. J. Saudi Chem. Soc. 2018, 22, 767. [CrossRef]

56. Burmeister, L.C. Convective Heat Transfer: Solutions Manual; John Wiley \& Sons, Incorporated: Hoboken, NJ, USA, 1993.

57. Haes, A.J.; Zou, S.; Schatz, G.C.; van Duyne, R.P. A nanoscale optical biosensor: The long range distance dependence of the Localized Surface Plasmon Resonance of noble metals nanoparticles. J. Phys. Chem. B 2004, 108, 109. [CrossRef]

58. Pal, N.B.; Kryschi, C. A facile one-pot synthesis of blue and red luminescent thiol stabilized gold nanoclusters. A through optical and microscopy study. Phys. Chem. Chem. Phys. 2015, 17, 21423. [CrossRef]

59. Mie, G. A contribution to the optics of turbid media, especially colloidal metallic suspensions. Ann. Phys. 1908, 25, 377. [CrossRef] 
60. Borchert, H.; Shevchenko, E.V.; Robert, A.; Mekis, I.; Kornowski, A.; Grubel, G.; Weller, H. Determination of nanocrystal sizes: A comparison of tem, saxs, and xrd studies of highly monodisperse copt3 particles. Langmuir 2005, 21, 1931. [CrossRef] [PubMed]

61. Kedzierska-Matysek, M.; Matwijczuk, A.; Florek, M.; Barlowska, J.; Wolanciuk, A.; Matwijczuk, A.; Chrusciel, E.; Walkowiak, R.; Karcz, D.; Gladyszewska, B. Application of FTIR spectroscopy for analysis of the quality of honey. In Proceedings of the BIO Web of Conferences, Krakow, Poland, 25-27 September 2017; EDP Sciences: Les Ulis, France, 2018. [CrossRef] 